Prepared for: Benjamin Massot and Paul Rowlett (eds) L'hypothèse d'une diglossie en France. Special issue, Journal of French Language Studies 23.1 (to appear 2013).

\title{
Do French Speakers Really Have Two Grammars? ${ }^{1}$
}

\author{
PAUL ROWLETT \\ University of Salford
}

\begin{abstract}
I consider variation within French and its status in speakers' mental grammars. I start with Massot's (2008) claim that, within relevant grammatical units, speakers in contemporary metropolitan France do not combine socio-stylistically marked $\mathrm{L}$ and $\mathrm{H}$ features, and his explanation of this in terms of diglossia (Ferguson 1959), that is, the idea that speakers possess two (in this case massively overlapping but not identical) 'French' grammars which coexist in their minds: one (français démotique, FD: acquired early, well, and in a naturalistic environment) comprises one set of grammatical features which generate unmarked forms and the marked L forms; the other (français classique tardif, FCT: learnt later, often unreliably, in a more formal context and under the influence of literacy) comprises a (partially) different set of grammatical features which generate the same unmarked forms as well as the marked $\mathrm{H}$ forms. Speakers switch between FD and FCT but do not use them both simultaneously, at least not within the context of an individual clause. While Massot's claim is controversial (see Coveney 2011), I provisionally accept that it is correct, and move on to consider his explanation. I review instances of variation for which I suggest Massot's model needs to be revised in order to account for the phenomenon of surface forms which can be generated by both putative grammars, and which are therefore superficially part of the overlap, but which have a different linguistic status in each and underlyingly are not therefore part of any overlap. I then reconsider Massot's two-grammar hypothesis, raising issues surrounding the extent of the overlap between them, the nature of the differences between them, and their respective statuses in the minds of speakers. I suggest that in view of their massive overlap, their nonrandom differences, and their contrasting cognitive statuses, it does not make sense to view both FD and FCT as autonomous grammars. Rather, I suggest that only FD is an autonomous grammar. Since the differences between FD and FCT are instantiations of naturally occurring developments usually conceptualised in terms of cyclic grammaticalisation and renewal (the $\mathrm{L}$ features of FD are innovations with respect to the $\mathrm{H}$ features of FCT), I suggest that FCT should be seen as a dependent grammatical 'bolt on' which encodes its conservatism in an abstract and economical way.
\end{abstract}

1. Acknowledgements: This article has developed from plenary lectures I was invited to deliver to the 19th Manchester-Salford Postgraduate Linguistics Conference, held in September 2010, and the colloquium Du Français et de l'Anglais aux langues du monde: Variation, Structure et Théorie du langage, held at Montpellier-Paul Valéry in June 2012. Some of the ideas in the first sections of this article initially appeared in a working paper in 2011. I am grateful to the organisers of the conferences for their kind invitations, to the audiences for their engagement with my topic, and to the reviewers of the working paper and the present article for detailed and useful feedback. My thanks also to Benjamin Massot for the opportunity to discuss these issues. I appreciate that our views differ on various points; all errors are my own.

Abbreviations used: $N E G=$ negative marker; IND = indicative; SUB = subjunctive; $\mathrm{COND}=$ conditional; IMP = imperfect; $\mathrm{Q}=$ interrogative feature; $\mathrm{PLD}=$ primary linguistic data; $L A D=$ language acquisition device. 


\section{INTRODUCTION}

Much has changed in recent years in the study of language variation and change. In the context of French it was once a commonplace to claim that there had been no significant syntactic change since the end of the seventeenth century, and that the label 'Modern French' reflected a three-century-long period of grammatical stability (Rowlett 2007:9). According to Gadet's (2009) survey of work in the area, this is at least in part due to the 'ideology of the standard' (Milroy \& Milroy 1985) which surrounds the French (of France), and, relatedly, to the fact that the use of linguistic corpora, especially in relation to the spoken language, developed later for French than, for example, English or Italian. ${ }^{2}$ The relatively recent interest in syntactic variation within specifically spoken French is very closely associated with the work of the late Claire Blanche-Benveniste's Groupe aixois de recherches en syntaxe (GARS) at the University of Provence which has looked at VP-related valency variation (micro-syntax) and CP-related discourse/pragmatic variation (macro-syntax), ${ }^{3}$ and has even placed a question mark over the status of the sentence as the fundamental unit of syntactic description. Work on syntactic variation has now broadened out beyond narrow normative written French and takes in: (i) social/stylistic variation within France (Armstrong 2001; Blanche-Benveniste with Martin 2010); (ii) French in contact situations (Spaëtt ed. 2010); (iii) diatopic variation outside France, including comparison with 'le français de référence' and across 'non-standard' varieties (Gadet and Jones 2008); and, more recently still, (iv) French as used in online/computer-mediated environments (van Compernolle 2008; Damar 2008; Doehler 2011; Stark 2011).

The article is organised as follows: section two illustrates syntactic variation in French and the 'variationist' approach to it; section three sets out an alternative account based on the notion of diglossia; section four demonstrates how surface forms can have two distinct sets of properties in the two putative grammars; section five explores the nature of the relationship between the two grammars that Massot proposes, and suggests an alternative to the twogrammar hypothesis; section six contains some concluding remarks.

\section{SYNTACTIC VARIATION IN FRENCH}

Syntactic variation in the French of contemporary France is the subject of a 2008 Paris $8 \mathrm{PhD}$ thesis by Benjamin Massot. Massot catalogues a number of familiar areas of syntactic variation in French. First, the preverbal negative marker ne co-exists with a null variant $\varnothing$ :

a. Jean ne vient pas.

b. Jean $\varnothing$ vient pas. ${ }^{4}$

Second, topical subjects can, but do not have to, be clitic left dislocated:

a. Jean arrive demain.

b. Jean, il arrive demain.

2. I return to the notion of the ideology of the standard below. See Durand ed. (2008) for examples of recent work in French corpus linguistics.

3. A reviewer raises the issue of what counts as syntactic variation, in particular in the context of the view that the underlying computational system is invariant and that all variation is therefore by definition related to lexical items. I would want to distinguish between variation with respect to individual contentive lexical items (e.g., free phonological variation between /zəmasje/ and /zəmaswa/ 'I sit down') and variation relating to functional categories (even if they are deemed to be 'lexical') which can impact on, for example, word order.

4. Seen as the contrast between an overt and a covert negative head, this is probably better described as lexical variation. I return to this in sections four and five to show a more radical variation, relating to underlying syntactic structure. 
Third, non-presuppositional yes-no interrogatives either display 'inversion' ${ }^{\prime 5}$ of the finite verb or the use of the interrogative marker est-ce que 'is it that':

(3) a. Est-il parti?

b. Est-ce qu'il est parti?

Fourth, exclamatives can be marked by (Ah) que . . ! or Qu'est-ce que . . . !:

(4) a. (Ah) que tu es belle!

b. Qu'est-ce que tu es belle!

Fifth, the first-person plural subject proform nous 'we' alternates with on 'one':
a. Nous allons partir.
b. On va partir.

Finally, in a number of specific (non-adjectival) contexts there is variation as to whether or not past participles show overt agreement for gender and number with a preceding direct object:
a. les lettres que j'ai écrites [ekrit]
b. les lettres que j'ai écrit [ekri]

See Zribi-Hertz (2011:236-7) for details of a wider range of areas of variation across different levels of grammar.

Uncontroversially, Massot (2008) notes that, in terms of sociolinguistic status, the variation illustrated in (1)-(6) is not free. Rather, in each case the (a) and (b) variants have more or less clearly marked and contrasting stylistic profiles: the (a) examples are high status $(H)$, while the (b) ones are low status (L). Further, given the absence of any immediately obvious unmarked (= both $\mathrm{H}$ and $\mathrm{L}$ ) alternative, speakers using these structures have no option other than to adopt an overtly $\mathrm{H}$ or $\mathrm{L}$ style. This contrasts with the situation illustrated in (7) and (8), where in (7) the unmarked variant in (7a) alternates with a highly marked $\mathrm{H}$ variant in (7b), and in (8) the unmarked variant in (8a) alternates with a highly marked $L$ variant in (8b). ${ }^{6}$

5. For the modern language there are important reasons not to think of the phenomenon illustrated in (3a) as inversion in the sense of movement of the finite verb to the left of the subject and out of the core clause. I therefore use scare quotes when using this label. See Rowlett (2007) for detailed discussion and an alternative analysis, based on the idea that, unlike in English for example, where the presence of the $Q$ feature on I*o (understood as the highest inflectional head position within the core clause) triggers movement, for checking purposes, of the finite verb to $C^{* \circ}$ (a head position within the left clause periphery), as in (i), in French the $Q$ feature on $I^{* \circ}$ instead creates a representational chain with $C^{* \circ}$, one of the consequences of which is that the finite verb can remain in $\mathrm{I}^{* \circ}$ and appear with an 'agreement affix', the element traditionally analysed as (and doubtless historically derived from) the subject proform, as in (ii):

(i) $\quad\left[\mathrm{CP}^{*} \mathrm{OP} \mathrm{Q}_{\mathrm{Q}} \mathrm{Vfin}_{\mathrm{Qi}}\left[\mathrm{PP}^{*}\right.\right.$ Subject $\left.\left.t_{\mathrm{i}}\left[\mathrm{vpP}^{*} \ldots \mathrm{t}_{\mathrm{i}} \ldots\right]\right]\right]$

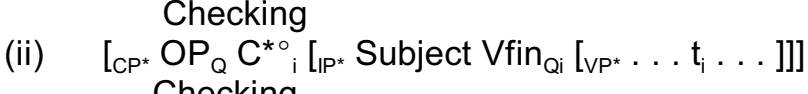
Checking

6. The highly marked nature of the examples in (7b) and (8b) should be stressed. One reviewer describes (7b) as obsolete/ridiculous/humourous, and (8b) as stigmatised to the extent of having become a 'shibboleth of uneducated speech'. Reviewers question the socio-stylistic judgements offered here, and suggest that the facts are more complex than is suggested by the simple $\mathrm{H}-\mathrm{L}$ dichotomy. While it is clear that the status of, say, (8b) differs from that of $(5 b)$, it is necessary to distinguish between status differences which derive directly from a grammar, and those which are due to socially entrenched prescriptivism, which have no grammatical basis (cf. split infinitives and dangling prepositions in English). 
(7)

(8) a. Si elle avait pu... UNMARKED: H AND L

a. Si elle avait su ... UNMARKED: H AND L b. Si elle eût pu...

MARKED: $\mathrm{H}$

b. Si elle aurait su ...

MARKED: L

Massot (2008) has a particular interest in the data in (1)-(8), namely the issue of how the attested variation is related to the grammar encoded in speakers' minds. According to one model, which might be labelled variationist, ${ }^{7}$ speakers have access to a single grammar which internally accounts for the attested variation: a number of loci of variation are embedded within the grammar, and for each one speakers make a choice on the hoof as to which (stylistically marked or unmarked) available variant to use in a particular utterance. Such an approach predicts that all logically possible combinations of variants are in principle available, and, in the case of the variation illustrated in (1)-(6), that speakers can freely combine marked $\mathrm{H}$ and marked L variants. Significantly, though, Massot (2008) shows that free co-occurrence of variants is not found. For example, with respect to the variation illustrated in (1) and (2) above, the variationist approach predicts that all four combinations of negation with $n e(\mathrm{H})$ versus negation without $n e(\mathrm{~L})$, and of no dislocation $(\mathrm{H})$ versus dislocation $(\mathrm{L})$, should be attested. Yet, they are not, as shown by the judgements in (9):
a. Jean ne vient pas.
b. $\quad$ ??*Jean vient pas. ${ }^{8}$
c. ??*Jean, il ne vient pas.
a-d: 'As for J., he's not coming.'
d. Jean, il vient pas.

While the grammatical (9a) illustrates the choice of two $\mathrm{H}$ options (no dislocation; ne present) and (9d) the choice of two L options (dislocation; ne absent), the ungrammatical (9b, c) represent the selection of two mismatching options, one $\mathrm{H}$ and one $\mathrm{L}$. This pattern of (un)grammaticality (or at least unacceptability) is not expected within the variationist model of variant selection within a single grammar, and Massot (2008) therefore rejects that model.

\section{FRANCE AS DIGLOSSIC}

As an alternative to the variationist approach based on choices available within a single grammar Massot (2008) suggests that the attested variation is a reflection of the fact that individual speakers have access to two distinct 'French' grammars, one of which is sociolinguistically/stylistically marked $L$, while the other is marked $H$. The data in (9) are therefore captured by two grammatical differences between the two varieties.

Various labels have been used in the literature to characterise $\mathrm{H}$ and $\mathrm{L}$ grammars/ varieties, for example, le français avancé, le néo-français, colloquial French, contemporary French or spontaneous French (L) contrasting with written French, modern French, or normed French $(\mathrm{H})$. Massot (2008) settles on the terms français démotique (FD) for the $L$ grammar, and français classique tardif (FCT) for the $\mathrm{H}$ variety. FD and FCT are characterised in (10a) and (10b) respectively:

7. The term 'inherently variationist' might be more appropriate in the sense that, e.g., Gadet (1996) and Hornsby (1998) [cited in Zribi-Hertz 2011:232] argue that speakers' grammars are inherently variable.

8. The grammaticality judgement in the text relates to the interpretation of the subject as topical (see the suggested English translation). If the subject is non-topical, and the whole sentence is focal, then the example is grammatical. This reading and this judgement are irrelevant for my purposes. 
(10) a. FD: an innovative but socially stigmatised vernacular acquired early in the naturalistic setting of the home and in which the speaker has a stable, active competence which might be described as that of a native speaker.

b. FCT: a conservative and more prestigious variety learnt later, under the influence of schooling and literacy, conscious instruction from caregivers and the normative tradition, and not necessarily to the same degree of stability (perhaps even only with a passive competence), and hence characterised by uncertainty and hypercorrection.

For Massot FD and FCT co-exist in each speaker's mind as two distinct and autonomous grammars. As we have seen, there is overlap (extensive but not total) between FD and FCT, and so some surface forms will be generated by both grammars and have the same grammatical properties in each: such areas of overlap, such as those in (7a) and (8a), will be sociolinguistically/stylistically unmarked (both $\mathrm{H}$ and $\mathrm{L}$ ); forms generated by FCT but not FD, such as those illustrated in (1a)-(6a) and (7b), will be prestigious, valued, normative $(\mathrm{H})$; forms generated by FD but not FCT, such as those illustrated in (1b)-(6b) and (8b), will be stigmatised, non-normative (L).

Massot's two-grammar account of the judgements in $(9 a-d)$ is based on the notion that only one of the two available sets of features (= grammars) can be accessed at one time, at least within the context of a single clause, ${ }^{9}$ and that the choice which the speaker makes will be made on the basis of a sociolinguistic assessment of the context. For our purposes, the model explains why, within the relevant unit, a speaker is unable to combine uniquely FD ( $L$ ) features with uniquely FCT $(\mathrm{H})$ features. In section five I suggest that the incompatibility of marked L and $\mathrm{H}$ features within a single clause can be explained without recourse to two grammars. But first, in section four, I propose a refinement to Massot's approach by considering surface forms which are generated by the two grammars posited, but which have different underlying structures depending on the source grammar.

\section{ONE SURFACE FORM, TWO GRAMMATICAL STATUSES}

Massot assumes, along with Zribi-Hertz (e.g. 2011:240-1) for example, that a surface form generated by both FCT and FD (and therefore stylistically/sociolinguistically unmarked) has the same grammatical properties in each. This is true of the structures illustrated in (7a) and (8a). However, it is not necessarily the case: one and the same surface form can have quite different grammatical properties in FCT and FD. For example, in her discussion of matrix wh interrogatives in Francilian French Hamlaoui (2011:134-5) contrasts in situ object wh questions as illustrated in (11) in the dialect described in Boeckx (1999) with her own dialect:

$$
\mathrm{T}(\mathrm{u}) \text { as acheté quoi? }
$$

In Boeckx's variety an answer to the question in (11) along the lines of Rien 'Nothing' is infelicitous, while in Hamlaoui's it is perfectly fine. In Boeckx's grammar (11) asks for the value of $x$, such that $x$ identifies an entity (and therefore presupposes that such an entity exists); in Hamlaoui's grammar it asks for the set of individuals (which can be empty). However this difference is captured in terms of abstract representation (an issue which is beyond the scope of this article), it is clear that one and the same surface form has distinct linguistic properties depending on which grammar generated it.

9. This claim is significant, since intra-sentential (as opposed to inter-sentential) code-switching is well attested in the literature (see for example van Gelderen and MacSwan 2008). The recent generative notion of syntactic phase may shed light on the relevant syntactic unit within which variation is not found. 
A second example of one form having different structures depending on its source grammar is noted by Massot himself (2008:208-22), in respect of negation. Massot gives the examples in (12) (his (19), p. 213):

$$
\begin{aligned}
& \text { a. Ça (ne) va pas être évident. } \\
& \text { 'It won't be straightforward.' }
\end{aligned}
$$

b. Ça (*ne) va être pas évident.

'It'll be not straightforward.'

I have tried to capture the subtle semantic contrast in the (somewhat awkward!) translations. The important feature is that $n e$ is optionally present in (12a), but necessarily absent in (12b). Massot's perfectly plausible approach is to say that, in the ne-less version of (12a), pas raises to NegP, thereby encoding wide-scope sentential negation, which means that $\mathrm{Neg}^{\circ}$ is generated but has a null realisation (see (13a)), while in the necessarily ne-less (12b), pas has narrow scope over évident, occupies a relatively low position in surface syntax (hence to the right of (= lower than) être) and is not associated with any NegP projection, hence the unavailability of ne (see (13b)).

(13) a.

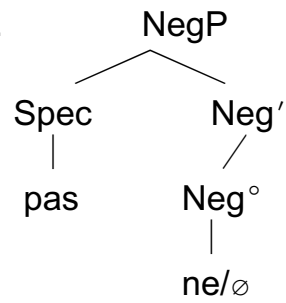

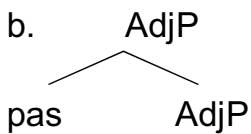

These two approaches to the syntax of pas mean that a superficially simple negative sentence like (14) is compatible with two analyses, one in which pas is associated with $\mathrm{NegP}$ and $\mathrm{Neg}^{\circ}$ is null, the other in which pas is a low, VP adverb, and in which NegP is not generated.

II vient pas.

In other words, a single surface form like (14) has different structures depending on its source grammar, and is therefore not in any real sense part of any overlap.

A final surface form which has two underlying structures depending on the grammar which generates it is est-ce que/qui 'is it that', ${ }^{10}$ found in interrogative sentences. Diachronically, estce que/qui is transparently the output of an overt (and presumably genuine - see footnote 5) syntactic inversion process which has applied to c'est que/qui 'it is that', a cleft structure marking pragmatic focus. Synchronically, things are not so straightforward. Est-ce que/qui is found in both FCT and FD, and in that sense might a priori be thought of along the same lines as (7a) and (8a): these can be generated by both grammars, and there is every reason to believe that they have the same grammatical status in each. This is Massot's approach to estce que/qui (see Massot 2010, Fig. 1). Yet for est-ce que/qui the approach is problematic. The problem does not lie so much within FCT: since this grammar is known to retain 'inversion' (see (3a) and footnote 5), we can assume that est-ce que/qui in FCT is an instance of an 'inverted' cleft. Rather, the problem lies within FD: FD has not retained 'inversion', and in fact est-ce que/ qui is presented in (3b) as the FD alternative to the 'inverted' FCT form. Est-ce que/qui is therefore deemed to have a different grammatical status in FD to the one it has in FCT. Rowlett (2007) adopts an analysis of est-ce que/qui in FD as a grammaticalised complementiser drawn from the lexicon ready made (Martinet 1960), and merged directly in a head position within the left clause periphery, without marking pragmatic focus. Thus, unlike Massot's (2010) approach, in which est-ce que/qui has the same syntactic and, presumably therefore, also pragmatic properties in both FCT and FD, two distinct analyses are posited for

10. The difference between que and qui in this form is a long-standing issue in French syntax, going back to Moreau (1971), but tangential to my concerns here. I gloss them both as that. 
est-ce que/qui which differ both syntactically (result of 'inversion' (FCT) or atomic complementiser (FD)?) and pragmatically (focus-cleft (FCT) or not focus-cleft (FD)?):

(15) a. Est-ce que tu pars? In FCT: biclausal; the consequence of the Q feature being merged on ${ }^{* \circ}$ in the matrix clause; an 'inverted' cleft expressing pragmatic focus.

b. Est-ce que tu pars? In FD: monoclausal; the consequence of the $Q$ feature being merged on $\mathrm{C}^{* \circ}$; therefore not inverted; therefore not expressing pragmatic focus.

The interaction between these two dimensions of variation is illustrated in (16) in the context of the question 'Who can you see?' (Rowlett 2007:210). ${ }^{11}$

\begin{tabular}{lll}
\hline & FCT $\left([\mathrm{Q}]\right.$ on $\left.\mathrm{I}^{* \circ}\right)$ & FD $\left([\mathrm{Q}] \text { on } \mathrm{C}^{* \circ}\right)^{12}$ \\
& & \\
& & Qui $[\varnothing]$ tu vois? \\
Non-cleft $\quad$ Qui vois-tu? & Qui [que] tu vois? \\
& Qui [est-ce que] tu vois? \\
& Qui [c'est que] tu vois? \\
& Qui [ø] c'est que tu vois? \\
Cleft & Qui est-ce que tu vois? & Qui [que] c'est que tu vois? \\
& & Qui [est-ce que] c'est que tu vois? \\
& & Qui [c'est que] c'est que tu vois? \\
\hline
\end{tabular}

Qui est-ce que tu vois? appears twice in (16) (italicised): bottom left it is generated by the FCT grammar within an inverted cleft with wh fronting; top right it is generated by an FD grammar within an uninverted non-cleft with wh fronting and the atomic complementiser est-ce que drawn from the lexicon. The question has a different pragmatic status depending on which grammar generated it. ${ }^{13}$

The two analyses of est-ce que/qui, one for FCT on the basis of syntactic 'inversion', another for FD without such a device, address several issues and these are set out in the following sections. The issues relate to double clefting, tense marking, 'inversion' in subordinate interrogatives and the parallel between est-ce que and si 'if'. In each case, it is shown how the data could not be captured if it were assumed that the same surface form has the same syntactic properties in both FCT and FD.

11. The set of variants in (16) excludes two which might be classed as 'wh in situ', namely: (i) a. Tu vois qui? $\quad$ b. C'est qui que tu vois?

Here, the wh phrase fails to front. For recent critical discussion of the pragmatic distinction reflected in the syntactic fronted vs. in situ distinction, see Hamlaoui (2011).

12. Not all speakers have all the atomic complementisers catalogued in this column. For example, [c'est que] is described as 'popular' and absent from some speakers' FD. Since these are lexical items, the absence of one from the paradigm does not have syntactic consequences.

13. The surface form Qui c'est que tu vois? also appears twice in the table (underlined), once top right, once bottom right, both generated by FD. In the first case c'est que is a complementiser within a non-cleft sentence; in the second case the complementiser is nonovert and c'est que marks a cleft. Even within the context of FD grammar, therefore, the surface form is ambiguous between two underlying structures, here differing in pragmatic terms. 


\subsection{Double clefting}

Consider the examples in (17) and (18), generated by an FD grammar, and taken from the bottom right-hand corner cell in the table in (16):

(17) Qui est-ce que c'est que tu vois?

(18) Qui c'est que c'est que tu vois?

If est-ce que in (17) were the result of 'inversion' in FD, as it is in FCT, then this example would be derived from the uninverted (and non-wh-fronted) structure in (19):

(19) C'est qui que c'est que tu vois?

This is problematic since the prospective underlying structure in (19) is characterised by two instances of clefting, a feature which is hard to motivate on pragmatic grounds. The same is also clearly true of (18). If, in contrast, and as suggested here, c'est que/qui and est-ce que/qui are used within an FD grammar as an atomic complementiser drawn directly from the lexicon, without the pragmatic force of a cleft, then there is no need to derive (17)/(18) from (19). Examples (17)/(18) are single, pragmatically motivated cleft sentences containing a formally complex, but syntactically atomic, complementiser.

\subsection{Tense marking}

The two analyses of est-ce que/qui, one within FCT and another within FD, make contrasting predictions in respect of tense marking. In FCT est-ce que/qui is an inverted cleft, and est a finite verb. As such, tense variation is expected (together with sequence-of-tense implications), as in the examples in (20), which run parallel to Qui est-ce que tu vois?, from the table in (16):

(20) a. Qui était-ce que tu voyais? (Imperfect)

b. Qui sera-ce que tu verras? (Future)

c. Qui serait-ce que tu verrais? (Conditional)

d. Qui fut-ce que tu vis? (Past-historic)

The phenomenon is quite rare, probably due to the anchoring of clefts to utterance time,${ }^{14}$ but the following are attested examples found online:

(21) a. Quand sera-ce que nous serons petits? (Future) (aiderpretres.cef.fr/index2.php?option=com_content\&do_pdf=1\&id=36; accessed 19 August 2012)

b. Qui était-ce qui avait préparé ... ? (Imperfect) (coptipedia.com/sa-saintete-le-pape-cyrille-vi/la-riviere-de-la-saintete.html; accessed 19 August 2012)

c. Quand serait-ce qu'elle arriverait? (Conditional)

(books.google.co.uk/books?id=6CXA-i0x3g0C; accessed 19 August 2012)

d. Quand fut-ce que notre Sauveur fit le plus grand service à son Père? (Past-historic) (www.clerus.org/bibliaclerusonline/es/i1y.htm; accessed 19 August 2012)

As expected given their FCT origin, the examples in (21) are stylistically marked as $\mathrm{H}$ (in

14. Examples like the ones in (20) were in fact condemned by Vaugelas in favour of alternatives with est-ce que/qui. 
addition to expressing pragmatic focus).

In FD est-ce que/qui is an atomic complementiser drawn ready made from lexicon; it does not express pragmatic focus; it does not contain a finite verb, and so tense-related variant forms are not expected. In other words, not only are the examples in (21) expected to be stylistically marked as $\mathrm{H}$, the FD equivalents are expected to contain one of the forms in the right-hand column of the table in (16), irrespective of the tense of the lexical verb, and this prediction is borne out, as illustrated in the examples in (22):

(22) a. Quand est-ce (que c'est) qu'on sera petits?

b. Qui est-ce (que c'est) qui avait préparé ... ?

(FD) cf. (21a)

c. Quand est-ce (que c'est) qu'elle arriverait?

(FD) cf. (21b)

d. ??Quand est-ce (que c'est) que notre Sauveur fit le plus grand service à son Père ${ }^{15}$

(FD) cf. (21d)

\section{3 'Inversion' in subordinate interrogatives}

The dual analysis of est-ce que/qui explains the mystery of the contrast in (23) (from Jones 1999:190):

(23) a. *Je me demande quand arrivera-t-il.

(FD/FCT)

b. Je me demande quand est-ce que le train arrivera.

$\left(\mathrm{FD} /{ }^{*} \mathrm{FCT}\right)$

Example (23a) shows that 'inversion' is impossible in subordinate interrogatives, in FCT and FD alike. This has been accounted for theoretically by claiming that, in both grammars of French (as indeed in standard English), in selected interrogative contexts like indirect questions the crucial $Q$ feature is merged high in the left periphery, that is, higher than in matrix interrogatives, and 'inversion' is therefore unmotivated. On that basis, the grammaticality in FD (although not in FCT) of (23b), containing est-ce que/qui, is possibly unexpected. Crucially, though, this is only the case if est-ce que/qui reflects 'inversion' in FD as it does in FCT. But, if, as suggested here, FD is not characterised by 'inversion', and if est-ce que/qui in FD is instead an atomic complementiser rather than the output of 'inversion', then nothing more needs to be said: 'inversion' in (23a) is ungrammatical for both grammars because $Q$ is merged high in subordinate interrogatives; est-ce que in (23b) is grammatical (in FD) because it is not generated by 'inversion' but is instead one of several available lexical realisations of the interrogative complementiser (alongside $\varnothing$, que and c'est que):

(24) a. Je me demande quand $\unrhd$ le train arrivera.

(FD/FCT)

b. Je me demande quand que le train arrivera.

c. Je me demande quand c'est que le train arrivera. $a-c:=(23 b)$

\section{4 'Est-ce que' vs. 'si'}

Finally, the claim that est-ce que/qui functions in FD as an atomic complementiser, rather than as the output of 'inversion', explains the two ways in which it parallels the uncontroversial complementiser si 'if'. The first is that est-ce que/qui is a direct FD equivalent of si 'if' as a marker of an indirect yes-no question, as in (25):

(25) a. II demande s'il pleut. (FCT/FD) b. II demande est-ce qu'il pleut. (FD)

15. The question-mark judgement against (22d) reflects the stylistic mismatch between the use of the est-ce que complementiser $(\mathrm{L})$ and the past-historic verb form $(\mathrm{H})$. 
The second is illustrated in (26), which Goosse (2000:114) characterises as oral and regionally marked (hence FD in our terms).

(26) [Est-ce que vous viendrez] ou [si c'est lui]?

Assuming a parallel structure across the two conjuncts of the conjunction, est-ce que and si both appear to function as a complementiser introducing a matrix interrogative. Crucially, such a parallel analysis would not be possible if est-ce que/qui were analysed here as the output of 'inversion'.

In short, therefore, there are at least four reasons not to conclude that the surface form est-ce que/qui has the same grammatical status in its two source grammars, and reasons to believe that superficially identical negative and matrix wh-interrogative forms have different underlying properties depending on which grammar generates them. Massot's diglossic approach to syntactic variation in French consequently needs to be revised to allow this: the term 'overlap', sometimes represented as intersecting sets, underestimates what is actually going on. In section five I show that the idea of one and the same form having different structures depending on which grammar has generated it is actually key to understanding diglossia.

\section{TWO GRAMMARS OR NOT TWO GRAMMARS?}

So far we have identified syntactic variation within modern French, rejected the variationist account of it on the grounds that it fails to explain why some combinations of variants are not attested, seen the diglossic approach as a potential alternative account which does not have this weakness, and added that the model needs to be flexible enough to allow, where appropriate, a surface form to have distinct properties in the two posited grammars (as well as allowing for structural ambiguity within one and the same grammar; see footnote 13). In this section I consider issues which suggest that the two-grammar model is too powerful for French. Those issues are: (a) the overlap between the two posited grammars; (b) the differences between the two grammars; and (c) the cognitive status of the two grammars. I then argue that these issues point to a rethink, not in terms of two grammars, but instead in terms of a single grammar together with what I shall term a grammatical 'bolt on'. The issues, and the alternative approach, are discussed in the following sections.

\subsection{Overlap}

The first issue which I suggest is problematic for the two-grammar approach to variation in French is the extent of the overlap between the two proposed grammars. The overlap between FD and FCT is massive, covering all levels of grammatical description (as well as the lexicon). In fact it is so extensive that not only are FD and FCT both commonly simply known as 'French' among non-linguists, but the existence of the difference in terms of distinct and discrete varieties is in fact not even generally acknowledged, at least not in the way that standard and dialectal Arabic are recognised as distinct varieties. And indeed the absence of this acknowledgement plays to the variationist approach to the empirical phenomena we are concerned with, in terms of grammar-internal flexibility.

The massive FCT-FD overlap in the specific context of French raises the more general question of whether there is a limit to the extent to which two or more varieties can overlap in terms of their grammatical (not to mention lexical) properties, yet still reliably be acquired by children, and subsequently maintained independently in the speaker's mind/brain. From the perspective of acquisition, the child, having first acquired FD, would need to notice, in the linguistic data to which s/he is exposed (e.g. through formal schooling), a surface distinctiveness above a threshold quality and quantity in order to conclude that the data was the 
output of a system distinct from FD. ${ }^{16}$ Where a child is growing up in a bilingual environment as more typically conceived of, exposed to and acquiring two quite different languages (as opposed to different varieties) in a naturalistic setting either from birth or at least from an early age, this is not an issue since the PLD generated by the two systems are presumably sufficiently qualitatively and quantitatively distinct. But it is not so clear in the case of two varieties of the same language which show significant overlap. The variationist approach to the empirical data we have been considering, based on a single grammar, does not have this problem: the different 'varieties' of French are as strikingly similar to one another as they are because they are generated by the same (albeit flexible) grammar. In the diglossic account of variation in French, where two distinct grammars are posited, the question is, Why are FD and FCT so similar?

\subsection{Non-overlap}

The second issue for the two-grammar approach relates not to their overlap but to how they differ, that is, their non-overlap. Massot (2008) makes clear that the FCT-FD distinction is not the same as the distinction between spoken and written language: uniquely FD and uniquely FCT features appear in written and spoken language alike; there is nothing inherent in the (distinctive) properties of FCT or FD which predisposes them to one particular channel; neither is there anything particular about speech or writing which explains why certain grammatical features are characteristic of FD or FCT. There would appear, therefore, to be no reason to assume anything other than random differences between FD and FCT, both in terms of the precise points of grammar where the differences are located, and in terms of the precise nature of the difference at each point. As one reviewer put it, in the two-grammar model FD could be as different from FCT as French and Chinese.

Yet FD and FCT are not as different as French and Chinese, and it is conceivable that the grammatical differences between FCT and FD are not random, either in terms of position or nature; it is possible that they are instead 'micro-' reflexes of an overarching 'macro-' contrast which can therefore be characterised at a higher level of abstraction. A suggestion that this might be the case comes, for example, from comments like those made by committed variationist Françoise Gadet: while not claiming that [FD] is a simplified version of [FCT], Gadet (1997) characterises [FD] in terms of a séquence progressive, fixed word order, analyticity, invariability. An indication of the nature of the non-random relationship between (?some of the properties of) FD and FCT is hinted at in the use of the labels 'conservative' for FCT and 'innovative' for FD. By definition relative, the labels suggest that properties of FD are a diachronic development of those of FCT. This is the case of the two analyses of est-ce que/qui: the status of the form in FD (with $Q$ in $C^{* \circ}$ underlyingly) indicates an innovative reanalysis, the result of the grammaticalisation of the FCT form (with $Q$ in $\mathrm{I}^{* \circ}$ underlyingly but linked to $C^{* \circ}$ via a representational chain). This also applies to the distinction between bipartite and postverbal monopartite negation within the context of Jespersen's negative cycle ${ }^{17}$ : a form

16. Some quantitative/qualitative threshold is needed, otherwise any PLD, for example, containing performance errors or the output of non-native competence, could potentially trigger the child to hypothesise a distinct grammar.

17. Jespersen's negative cycle is the diachronic phenomenon illustrated by the French development in (i), in which a preverbal/head negative marker is initially strengthened and then replaced by a postverbal/phrasal negative marker:

(i) a. jeo ne di.

b. je ne dis (pas).

c. je ne dis pas.

d. je (ne) dis pas.

e. je dis pas. 
like II vient pas 'He's not coming' has a different structure depending on whether the grammar generating it is at one stage within the cycle (NegP projected with a null head: II ne/ø vient pas) or at the next one (NegP not projected: I/ vient pas; see example (13)). And it applies to the reanalysis of subject proforms as agreement markers within the context of van Gelderen's (2011:38ff.) agreement cycle: subject pronominals are reanalysed as verbal agreement markers which can then co-occur with, for example, DP or emphatic pronoun subjects without pragmatic topicalisation or syntactic dislocation; co-ordinated VPs have obligatorily repeated 'subjects', as in (27a), and il can be anaphoric on indefinite antecedents, as in (27b):

$$
\text { a. Je lis et *(j')écris. }
$$

b. Tout le monde/Personne il est beau. ( ${ }^{*}$ in FCT)

While it would doubtless be inappropriate to suggest that FD is a straightforward descendent of FCT, if they are deemed to be the output of two independent grammars, then the question to be answered is, Why does so much of the FD-FCT contrast appear to be amenable to a single overarching generalisation of FD being innovative with respect to FCT?

\subsection{Cognitive status of FCT}

The third issue to be addressed by the two-grammar model has to do with the cognitive status of the two posited grammars, in particular, the status of FCT. FD is characterised in (10a), and its status as a cognitively real grammar, the product of the language acquisition device, encoded in the mind/brain of speakers therefore seems unproblematic. FCT, in contrast, is characterised in (10b). It is not acquired early in a naturalistic environment, and is dependent on literacy and formal schooling; speakers commonly only have a passive competence of FCT, characterised by uncertainty (e.g., le fait que 'the fact that . . . ' followed by IND rather than standard SUB) and hypercorrection (e.g., après que 'after ... .' followed by SUB rather than standard IND, by analogy with avant que 'before ... ' which has SUB in the standard ${ }^{18}$ ). The status of FCT in the mind/brain of speakers is therefore less clear, and doubts have been cast as to its cognitive reality and coherence for some time (Bauche 1928; Côté 1999). FCT has also been the subject of artificial interference from the Académie française, for example, with respect to present- and past-participle agreement as well as the mood found in finite subordinate clauses selected by concessive conjunctions or bridge verbs (including in respect of the judgements given above; Rowlett 2007:7). From such perspectives, as well as from the perspective of Ferguson's original sociolinguistic notion of diglossia amounting to relatively stable co-existence of two varieties, the question is, Can FCT really be thought of as (the output of) a separate, independent grammar?

\subsection{An alternative approach}

In this section I endeavour to capture the essential insight of the diglossic approach to variation in French - namely the judgements in (9) - while addressing the issues raised above. The idea is as follows. As per (10a) the child is exposed to PLD in the naturalistic context of the home and family, and acquires the grammar of a vernacular variety labelled here FD. Later, as per $(10 \mathrm{~b})$, the child notices that they are being exposed to a subtly different kind of linguistic input, labelled here FCT, which is incompatible with the (FD) grammar previously acquired

The cycle is closed when the postverbal/phrasal negative marker is in turn reanalysed as a head marker; this final stage has not (yet?) happened with respect to French pas.

18. Benjamin Massot (personal communication) suggests that the status of après que 'after ...' followed by SUB rather than standard IND is the same as that of dangling prepositions and split infinitives in English, that is, perfectly grammatical but socially stigmatised, and only reliably avoided on the basis of intensive drilling and close self-monitoring. 
(containing non-dislocated topical nominal subjects, negative $n e,{ }^{19}$ for example).

Over time the child develops a sensitivity to the relative socio-stylistic status of FD and FCT, and employs them differentially on the basis of assessments of situational appropriateness. The child (or, more specifically, their LAD) notices, however, that FCT is not randomly different from FD. In fact, in line with the notion that FD represents a diachronic innovation with respect to FCT, guided (in terms of direction of change if not in terms of rate of change) by UG-internal principles (van Gelderen 2011:377), the child ('s LAD) notices that the properties of relevant functional items in FCT correspond to a predecessor variety of FD. ${ }^{20}$ Since the child can conceptualise the relationship between FD and FCT in this way, they do not need to posit/acquire a full, stand-alone grammar for FCT alongside the one for FD; rather, they can (and, for reasons of economy, therefore should) define/acquire FCT in the relative terms of how it compares to FD. I label the specification of FCT a grammatical 'bolt on' in order to capture the two ideas (a) that it is not defined autonomously in absolute terms, but only in terms relative to FD, and (b) that it is more concise/economical than a full grammar. The 'bolt on' contains a grammatical specification of where and how FCT differs from FD, but has nothing to say about where they are the same, and therefore is not a fully specified grammar. For the child who has already acquired FD, acquisition of FCT is therefore acquisition of this 'bolt on' rather than of a second grammar (or lexis), and the child's LAD does not then need to go through the steps in (28):

(28) a. creating a second grammar initially by copying the first;

b. modifying the copy as required, in order to take account of the problematic input; and

c. maintaining the two grammars independently of each other and indefinitely, not only in terms of where they differ, but also in terms of where they overlap.

And code-switching between FD and FCT is not switching between two independent grammars, but rather engaging (or disengaging or failing to engage) the 'bolt on', which speakers do on the basis of an assessment of the situation.

The answers I propose to the questions posed at the end of each of the sections above are therefore as follows:

(29) a. FCT is as similar as it is to FD because, rather than being an independent grammar, FCT has FD at its core, and only differs from FD to the limited extent that the content of the grammatical 'bolt on' specifies that it differs.

b. The differences between FD and FCT are amenable to analysis in terms of overarching principles because they are the expression at the micro level of a single set of differing properties (or maybe even just one differing property) specified at the macro level within the grammatical 'bolt on' rather than within an independent grammar.

c. FCT is not a separate, independent grammar; rather, it is essentially FD which has been modified on the basis of the content of the grammatical 'bolt on'.

The 'bolt on' approach to French diglossia crucially differs from the 'inherently variable' approach since the former, unlike the latter, accounts for the non-randomness of the

19. Palasis (this volume) suggests that negative ne is one of the crucial superficial features which trigger the child to hypothesise a grammatical system alongside FD.

20. A reviewer questions how a child, or their LAD, could have a notion of diachronic precedence. I deem this notion to rely on nothing more than the same UG principles which determine, for example, the direction of change seen in clines of grammaticalisation. 
location/nature of the variation, as well as the judgements in (9). The approach raises a number of issues: 1 . For example, by closely examining the nature of what is referred to above as the non-overlap, which for FCT is encoded within a grammatical 'bolt on', and by endeavouring to capture with minimal mechanical apparatus, we can explore the architecture of grammar across various levels of description.

2. Beyond accounting for French diglossia, the notion of a grammatical 'bolt on' can offer an insight into situations of grammars in competition and/or periods of grammatical change in progress. The ongoing co-existence of FD (as a regular grammar) and FCT (as a 'bolt on') can be regarded as an (extended) period of change in progress. This should come as no surprise since the grammaticalisation theory and the model of grammars in competition rely on the possibility of a single form being compatible with more than one analysis, and of the diachronic drift from one analysis to another being driven by UG-internal principles. In the specific context we have been considering, the lifespan of the change in progress has been (artificially?) extended as a consequence of the social-political-cultural status of FCT within the specific context of the recent history of France (see Milroy \& Milroy's 1985 notion of the ideology of the standard).

3. By conceptualising the various dimensions of the FCT-FD contrast in terms of an immediately adjacent position around a cyclic pattern of development, or along a cline, a framework is provided for linking the dimensions with each other: we might think of the separate cycles as being exponents of a single overarching cycle. Rowlett (1996, 1998: chapter 3 ) tries to link the negative cycle and agreement cycle along these lines. The theoretical challenge is determining just how minimal the specification contained within the 'bolt on' can be.

4. Since the decision whether or not to activate the FCT 'bolt on' is culture-specific and can also be the expression of individual personality, it allows for differential patterns of linguistic behaviour across French-speaking communities, as illustrated in individual/groupbased differential rates of occurrence of marked $\mathrm{H}$ and marked $\mathrm{L}$ variants.

5. Also, within the overall Francophone community it is possible that different smallerscale speech communities have slightly different versions for FCT and FD. For example, De Cat (2007) notes that ne retention is higher amongst French speakers in Belgium than in France, while Goosse (2000:118) notes that negative imperatives like the one in (30) are not found in Belgian French:

\section{Parle-moi pas !}

These two observations are plausibly linked. FD and FCT for speakers of Belgian French could both be more conservative than they are for speakers in France, as illustrated by the table in (31):

\begin{tabular}{|l|l|l|}
\hline & FD & FCT \\
\hline \hline France & II vient pas (no NegP) & II (ne) vient pas (optionally null Neg ${ }^{\circ}$ ) \\
\hline \hline Belgium & II ø vient pas (null $\mathrm{Neg}^{\circ}$ ) & II ne vient pas (overt $\mathrm{Neg}^{\circ}$ ) \\
\hline
\end{tabular}

All other things being equal, this would lead us to expect Belgian French to have more ne retention (Belgian speakers using FCT would have overt ne while their French counterparts might have a null negative head) but no negative imperatives like (30) (the Belgian FD grammar projects NegP, which is necessarily absent in structures like (30); see Rowlett forthcoming). But in both the French and the Belgian scenarios, FCT is 'one stage more conservative' than FD, and so the same overall approach to the relationship between FD and FCT can be adopted. 


\section{SUMMARY AND CONCLUSION}

The starting point for the present article has been (a) the attested dimensions of (primarily syntactic) variation in French, (b) the (uncontroversial) notion that variation along some dimensions is socio-stylistically marked $\mathrm{H}$ or $\mathrm{L}$, and (c) the (more controversial) contention that much of this variation is not random. Under (c) in particular, it has been suggested (Massot 2008 ) that marked $\mathrm{H}$ features do not co-occur with marked $\mathrm{L}$ features. This state of affairs is accounted for by Zribi-Hertz (e.g. 2011; this volume) and her collaborators in terms of diglossia, that is, the idea that speakers have internalised two grammars, one of which (FCT) is associated with the marked $\mathrm{H}$ features, while another (FD) is associated with marked $\mathrm{L}$ features, and that, at least within the context of a single linguistic unit, which Massot claims is the clause, speakers use one grammar or the other, but not both, and therefore are prevented from combining marked $\mathrm{H}$ and marked $\mathrm{L}$ features. The existence of grammatical features which are $\mathrm{H} / \mathrm{L}$-neutral, which can combine with marked $\mathrm{H}$ or marked $\mathrm{L}$ features, is accounted for by assuming overlap between FD and FCT.

On this basis, I endeavoured to demonstrate that the notion of overlap between FD and FCT and the idea that a variety of surface forms can be generated by both FD and FCT fail to acknowledge the fact that some superficially identical surface forms have a different set of grammatical properties depending on whether they are generated by FD or FCT. The example of this that we saw in detail was the interrogative est-ce que/qui, which is an atomic complementiser in FD, but the output of a syntactic 'inversion' process applied to a biclausal cleft structure in FCT. Other examples included negation and in situ wh questions.

I then questioned the notion that FD and FCT are the product of two separate grammars in the mind/brain of speakers. This line of enquiry was based on (a) the extent of the overlap between FD and FCT (massive), (b) the way FD and FCT are acquired and their cognitive status for speakers (see $(10 a, b)$ ), as well as (c) the suggestion that FD and FCT do not differ randomly. In respect of (c) it was suggested that FD was grammatically innovative. This means that where FD and FCT differ, FCT is conservative with respect to FD, and that where a single superficial form has a different structure in FD and FCT, the form in FCT is again conservative with respect to FD. Further, innovation-conservatism along each dimension of variation was conceptualised as adjacent positions around a cyclic pattern of diachronic development: the relevant feature specifications of FD are the natural successors of those of FCT as determined by internal economy principles and learner bias (van Gelderen 2011).

Instead, therefore, of positing two grammars in the speaker's mind/brain, one for FD and another for FCT, I suggest that a more economical approach to the FD-FCT distinction is to assume that, subsequent to the acquisition of an FD, the child acquires an FCT 'bolt on' which, rather than capturing a full FCT grammar, is dependent on the FD grammar and merely captures how FCT differs from FD. The child posits a 'bolt on' of this kind because the linguistic input which is incompatible with their FD grammar is nevertheless recognised as being structurally related to the grammar of FD.

Having acquired the FCT 'bolt on' and evaluated its socio-stylistic status, the speaker is then in a position to decide when and where to activate the FCT bolt on, on the basis of his/her assessment of the pragmatic context. If the FCT 'bolt on' is not activated, the 'pure' FD grammar is used, and unmarked as well as marked L variants are produced; if the FCT 'bolt on' is activated, the marked FD $(=\mathrm{L})$ settings/values are overridden and the marked FCT $(=\mathrm{H})$ variants are found. Those (unmarked) features of genuinely 'superordinate' French, common to FD and FCT in superficial form and underlying structure, are unaffected by whether or not the FCT 'bolt on' is activated.

Looking ahead, the next stage of reflection within this approach to diglossia would be to enter into the detail of, for example, van Gelderen (2011) with her analysis of grammatical cycles in terms of macroparameters of agreement and structural case and, where appropriate, minor cycles related to interpretable or uninterpretable features in specifier and head position within NegP, DP and other relevant functional projections. The challenge for the 'bolt on' alternative to a second grammar is to push the economy approach to the FD-FCT relationship as far as possible with the difference encoded at as high a level of abstraction as is able to 
capture the empirical facts. I hope to be able to address this in future work.

Address for correspondence:

Paul Rowlett

School of Humanities, Languages \& Social Sciences

University of Salford

Salford M5 4WT

Greater Manchester

United Kingdom

e-mail: P.A.Rowlett@salford.ac.uk

\section{REFERENCES}

Armstrong, N. (2001). Social and Stylistic Variation in Spoken French: A Comparative Approach. Amsterdam: Benjamins.

Bauche, H. (1928). Le Langage populaire. Paris: Payot.

Blanche-Benveniste, C., with Martin, P. (2010). Le Français: usages de la langue parlée. Louvain: Peeters.

Boeckx, C. (1999). Decomposing French questions. The University of Pennsylvania Working Papers in Linguistics 6:69-80.

van Compernolle, R. A. (2008). Morphosyntactic and phonological constraints on negative particle variation in French-language chat discourse. Language Variation and Change 20:317-39.

Coveney, A. (2011). A language divided against itself? Diglossia, code-switching and variation in French. In Le français en contact: hommages à Raymond Mougeon, eds F. Martineau \& T. Nadasdi, pp. 51-85. Québec: Presses de l'Université Laval.

Côté, M.-H. (1999). Issues in the analysis and acquisition of clitics in (spoken) French. Ms. MIT.

Damar, M.-E. (2008). Le Subjonctif: norme et représentations de la norme dans le discours des internautes. Français Moderne 76:83-96.

De Cat, C. (2007). French Dislocation: Interpretation, Syntax, Acquistion. Oxford University Press.

Doehler, S. (2011). 'Hallo! Voulez vous luncher avec moi hüt? Le "Code switching" dans la communication par SMS', Linguistik Online 48.

Durand, J. (ed.) (2008). Le Français à la lumière des corpus. Special issue of Journal of French Language Studies 18.1.

Ferguson, C. A. (1959). Diglossia. Word 15:325-40.

Gadet, F. (1996). Niveaux de langue et variation intrinsèque. Palimpsestes 10:17-40.

Gadet, F. (1997). Le Français ordinaire. 2nd ed. Paris: Colin.

Gadet, F. (2009). Stylistic and syntactic variation: introduction. In Beeching, K., Armstrong, N. and Gadet, F. (eds) Sociolinguistic Variation in Contemporary French. Amsterdam: Benjamins. 115-20.

Gadet, F. \& Jones, M. C. (2008). Variation, contact and convergence in French spoken outside France. Journal of Language Contact 2:238-48.

van Gelderen, E. (2011). The Linguistic Cycle: Language Change and the Language Faculty. Oxford University Press.

van Gelderen, E. \& MacSwan, J. (2008). Interface conditions and code-switching: pronouns, lexical DPs, and checking theory. Lingua 118:765-76.

Goosse, A. (2000). Evolution de la syntaxe. In Antoine, G. and Cerquiglini, B. (eds) Histoire de la langue française 1945-2000. Paris: CNRS. 107-45.

Hamlaoui, F. (2011). On the role of phonology and discourse in Francilian French wh questions. Journal of Linguistics 47:129-62.

Hornsby, D. (1998). The dynamic model and inherent variability: the case of northern France. Journal of Applied Linguistics 6:19-36.

Jones, M. A. (1999). Subject-clitic inversion in inflectional hierarchies. Journal of French Language Studies 9:181-209.

Martinet, A. (1960). Eléments de linguistique générale. Paris: Armand Colin. 
Massot, B. (2008). Français et Diglossie: décrire la situation linguistique française contemporaine comme une diglossie: arguments morphosyntaxiques. Doctoral thesis. University of Paris 8. [Available for download at http://tel.archives-ouvertes.fr/tel00726999]

Massot, B. (2010). Le Patron diglossique de variation grammaticale en français. In Barra-Jover, M. (ed.) Le(s) Français: formaliser la variation. Langue Française 168:1-148. 87-106.

Milroy, J. \& Milroy, L. (1985). Authority in Language: Investigating Language Prescription and Standardisation. London: Routledge.

Moreau, M.-L. (1971). «L'homme que je crois qui est venu»; qui, que: relatifs et conjonctions. Langue Française 11:77-90.

Palasis, K. (This volume). The case for diglossia: describing the emergence of two grammars in the early acquisition of metropolitan French.

Rowlett, P. (1996). Negative Configurations in French. DPhil diss., University of York, UK. Circulated as University of Salford European Studies Research Institute Working Papers in Language and Linguistics 11. [Available for download at usir.salford.ac.uk/14973]

Rowlett, P. (1998). Sentential Negation in French. Oxford University Press. [Available for download at usir.salford.ac.uk/2703]

Rowlett, P. (2007). The Syntax of French. Cambridge University Press. [Available for download at usir.salford.ac.uk/1355]

Rowlett, P. (2011). Syntactic variation and diglossia in French. Salford Working Papers in Linguistics and Applied Linguistics 1:13-26. [Available for download at usir.salford.ac.uk/ 17553]

Rowlett, P. (Forthcoming). French imperatives, negative ne, and non-subject clitics. In Stark, E., Meisner, C. \& Völker, H. (eds) Negation and clitics in French and Romance: what kind of interaction? Selected papers from Negation and clitics in Romance, Zurich, Feb 2012.

Spaëtt, M. (ed.) (2010). Le Français au contact des langues: histoire, sociolinguistique, didactique. Special issue of Langue Française 167.

Stark, E. (2011). 'La Morphosyntaxe dans les SMS suisse francophones: Le Marquage de l'accord sujet-verbe conjugué', Linguistik Online 48.

Zribi-Hertz, A. (2011). Pour un modèle diglossique de description de français: quelques implications théoriques, didactiques et méthodologiques. Journal of French Language Studies 21:231-56.

Zribi-Hertz, A. (This volume). De la notion de grammaire standard dans une optique diglossique du français. 